\title{
Evaluation of Knowledge and Practice of Nursing Staff Regarding Immediate Care after Birth in Kirkuk City Hospitals
}

\author{
Darya Y.Mustafa* \\ Salwa Hazim Al-Mukhtar**
}

\begin{abstract}
Background and aim: The first hours days and weeks after child birth are a dangerous time for mother and newborn most death occur during or immediately after childbirth. This study aimed to evaluate knowledge and practices of nursing staff regarding immediate care after birth in Kirkuk city hospitals

Materials and method: A descriptive study was carried out from first October 2013 to first October 2014. The study carried out at two hospitals in Kirkuk city. The study sample consists of (50) midwives and nurses. A questionnaire was comprised of two parts: demographic data and questionnaire to evaluate the midwives knowledge regarding mother and newborn baby care immediately after birth and observational checklist to evaluate the midwives and nurses practice. Content validity was determined by presenting the items to panel of. Reliability of the questionnaire (tool)

Results: the study finding indicates that there was adequate knowledge of midwives -nurse immediately after birth and accepted practice.

Conclusion: the study concludes that midwives and nurses have adequate knowledge regarding mother and newborn baby immediately after birth. Midwives and nurses have accepted practice during providing care for mother and newborn baby immediately after birth.

Recommendation: training courses inside and outside country for midwives and nurses about giving care to mother and newborn baby to improve the quality of nursing care that provided to mothers and newborn immediately after birth.
\end{abstract}

Keywords:_midwives-nurses, knowledge, practice

\section{INTRIDUCTION}

Parturition or labour is a physiological process during which the products of conception that is the fetus, membranes, umbilical cord and placenta, are expelled outside of the uterus (Yvonne, 2009).

Labour is divided into four stages. The first stage from the onset of true labour pains and ends with full dilatation of cervix. The second stage starts from the full dilatation of cervix and ends with expulsion of the fetus from the birth canal. The third stage begins after the expulsion of fetus ends with expulsion of the placenta and membranes. The fourth stage is the stage of early recovery; it begins after the expulsion of placenta (Mirnalini, 2012).

The fourth stage of labor occurs immediately after the delivery of the placenta. It usually lasts for about 1 to 4 hours, and it initiates the postpartum period. During this stage the woman should be monitored closely because her body has just undergone many changes. In this stabilization phase, the uterus makes its initial readjustment to non- pregnant state. (Bendetti, 2002)

It is a very crucial time for both mother and the baby both are not recovering only from physical process of birth but also becoming acquainted with each other (Paul, 2004).

Midwives and nurses Frequently check the woman's physical well being, her blood loss, feel if the uterus is contracting, possibly take her blood pressure and pulse as well as check the woman's genitals for any tears or grazes. Because there can occur some life threatening complications during immediate postpartum period (Troy, 2003).

According to the World Health Organization (WHO, 2010) the majority of all neonatal death (75\%) occur during the first week of life. These deaths between (25\%) and (45\%) occur in the first 24 hours (Abdel Kareem, 2008) Quality health care immediately after the critical period of labour and delivery is the most important intervention for preventing maternal and neonatal morbidity and mortality to measure the quality of health care services based on patient health outcome. (Hoda et. al., 2012). The study aimed to evaluate nurses and midwives' knowledge and practice, and to find out the association between midwives - nurses' knowledge.

\section{MATERIALS AND METHOD}

A descriptive study was carried out, the

\footnotetext{
* MSc Candidate / College of Nursing/University of Kirkuk

** Assistant Professor/College of Nursing/University of Mosul .
} 
study conducted during the period from $1^{\text {st }}$ october 2013 to $1^{\text {st }}$ October 2014. The study carried out at two hospitals in Kirkuk city namely. Azadi teaching hospital and Kirkuk general hospital. The target population was midwives and nurses who working in delivery and recovery room. The study sample consist (37) midwives and (13) nurses. The questionnaire and observational checklist were used as mean of data collection. It comprised (3) major parts. Part one was presented in the sociodemographic data which include different items on general information about midwives -nurses. Part two include questionnaire to evaluate midwives- nurses' knowledge regarding mother care immediately after birth (after delivery of

\section{RESULTS}

Table (1): Demonstrates Socio-demographic characteristics for the Whole Study Sample

\begin{tabular}{|c|c|c|c|}
\hline \multicolumn{2}{|l|}{ Variables } & Frequency $(f)$ & Percentage $(\%)$ \\
\hline \multirow{3}{*}{ Age } & 20-29 year & 18 & 36 \\
\hline & $30-39$ year & 20 & 40 \\
\hline & More than 40 year & 12 & 24 \\
\hline \multicolumn{2}{|r|}{ Total } & 50 & 100 \\
\hline \multicolumn{4}{|c|}{ Mean \pm SD $=16.67 \pm 4.16$} \\
\hline \multicolumn{2}{|c|}{\begin{tabular}{|c|} 
Total \\
\end{tabular}} & 50 & 100 \\
\hline \multirow{3}{*}{ Level of education } & $\begin{array}{c}\text { Secondary nursing } \\
\text { school/midwifery }\end{array}$ & 37 & 74 \\
\hline & Secondary nursing school/ nursing & 12 & 20 \\
\hline & Nursing institute & 3 & 6 \\
\hline \multicolumn{2}{|r|}{ Total } & 50 & 100 \\
\hline \multirow{4}{*}{$\begin{array}{l}\text { Years experiences in } \\
\text { midwifery }\end{array}$} & Less than 5 years & 33 & 66 \\
\hline & $5-10$ years & 6 & 12 \\
\hline & $11-15$ years & 6 & 12 \\
\hline & More than 15 & 5 & 10 \\
\hline \multicolumn{2}{|r|}{ Total } & 50 & 100 \\
\hline
\end{tabular}

Table (2): Distribution of the participant's knowledge items mean score regarding mother and newborn care after immediately after birth $(\mathbf{N}=50)$

\begin{tabular}{|c|c|c|c|c|c|c|c|}
\hline \multirow{2}{*}{$\begin{array}{l}\mathbf{N} \\
\mathbf{O} .\end{array}$} & \multirow{2}{*}{ Item related to care of mother } & \multicolumn{2}{|c|}{ Yes } & \multicolumn{2}{|c|}{ No } & \multirow{2}{*}{ MS } & \multirow{2}{*}{ E. } \\
\hline & & $\mathbf{F}$ & $\%$ & $\mathbf{F}$ & $\%$ & & \\
\hline & Prevention of bleeding & & & & & & \\
\hline 1. & $\begin{array}{l}\text { Uterus massage after delivery of placenta help } \\
\text { the uterus to contract }\end{array}$ & 35 & 70 & 15 & 30 & 1.7 & Adequate \\
\hline 2. & $\begin{array}{l}\text { Fundal height of uterus it above the umbilical } \\
\text { cord after birth }\end{array}$ & 21 & 42 & 29 & 58 & 1.5 & Adequate \\
\hline 3. & Oxytocin is given to mother to prevent bleeding & 44 & 88 & 6 & 12 & 1.8 & Adequate \\
\hline 4. & $\begin{array}{l}\text { Vaginal blood contain small clot and mucus } \\
\text { after birth }\end{array}$ & 30 & 60 & 20 & 40 & 1.9 & Adequate \\
\hline 5. & $\begin{array}{l}\text { Bladder em “pty after birth decrease the } \\
\text { occurrence of bleeding }\end{array}$ & 47 & 94 & 3 & 6 & 1.9 & Adequate \\
\hline & Breast feeding & & & & & & \\
\hline 6. & breast feeding initiate after 2 hours after birth & 28 & 56 & 22 & 44 & 1.4 & Inadequate \\
\hline
\end{tabular}




\begin{tabular}{|c|c|c|c|c|c|c|c|}
\hline 7. & All mother encouraged to breast feed after birth & 32 & 64 & 18 & 36 & 1.6 & Adequate \\
\hline 8. & Breast feeding increase immunity of newborn & 40 & 80 & 10 & 20 & 1.9 & Adequate \\
\hline \multirow[t]{2}{*}{9.} & $\begin{array}{l}\text { Breast feeding is the best way to maintain body } \\
\text { Temp. }\end{array}$ & 28 & 56 & 22 & 44 & 1.4 & Inadequate \\
\hline & Skin to skin contact & & & & & & \\
\hline 10. & $\begin{array}{l}\text { Skin to skin contact between mother and } \\
\text { newborn occur after } 1 \mathrm{hr} \text { after birth }\end{array}$ & 35 & 70 & 15 & 20 & 1.3 & Inadequate \\
\hline 11. & $\begin{array}{l}\text { Skin to skin contact is important for newborn } \\
\text { breast feeding }\end{array}$ & 34 & 68 & 16 & 32 & 1.6 & Adequate \\
\hline \multirow[t]{2}{*}{12.} & $\begin{array}{l}\text { Skin to skin contact important for prevent of } \\
\text { newborn heat lose }\end{array}$ & 21 & 42 & 29 & 58 & 1.9 & Inadequate \\
\hline & Air way clearance & & & & & & \\
\hline 13. & $\begin{array}{l}\text { Holding of newborn head down help to } \\
\text { drainage the fluid from the infant chest }\end{array}$ & 36 & 72 & 14 & 28 & 1.7 & Adequate \\
\hline \multirow[t]{2}{*}{14.} & $\begin{array}{l}\text { Each newborn baby need suction with bulbe } \\
\text { syringe }\end{array}$ & 14 & 28 & 36 & 72 & 1.2 & Inadequate \\
\hline & Baby identification & & & & & & \\
\hline 15. & $\begin{array}{l}\text { Identification band put immediately before } \\
\text { cutting the cord }\end{array}$ & 11 & 22 & 39 & 78 & 1.9 & Adequate \\
\hline 16. & The band should include mother name only & 30 & 60 & 20 & 40 & 1.4 & Inadequate \\
\hline
\end{tabular}

Table (3): Distribution of the participant's practice items mean scores regarding mother and newborn baby care immediately after birth $(\mathrm{N}=50)$

\begin{tabular}{|c|c|c|c|c|c|c|c|c|c|}
\hline \multirow{2}{*}{ NO. } & \multirow{2}{*}{ Practice item of mother care } & \multicolumn{2}{|c|}{ Talways } & \multicolumn{2}{|c|}{ sometime } & \multicolumn{2}{|c|}{ never } & \multirow{2}{*}{ MS } & \multirow{2}{*}{ E. } \\
\hline & & $\mathbf{F}$ & $\%$ & $\mathbf{F}$ & $\%$ & $\mathbf{F}$ & $\%$ & & \\
\hline 1. & $\begin{array}{l}\text { Hand washing during contact with } \\
\text { mother }\end{array}$ & 18 & 36 & 20 & 40 & 12 & 24 & 2.1 & Accept \\
\hline 2. & $\begin{array}{l}\text { Hand washing during contact with } \\
\text { newborn }\end{array}$ & 8 & 16 & 14 & 28 & 28 & 56 & 1.6 & Poor \\
\hline 3. & Using sterile instrument & 35 & 70 & 10 & 20 & 5 & 10 & 2.6 & Good \\
\hline 4. & Inspect the placental membrane & 31 & 62 & 10 & 20 & 9 & 18 & 2.7 & Good \\
\hline 5. & Uterus massage & 35 & 70 & 13 & 26 & 2 & 4 & 2.6 & Good \\
\hline 6. & Observe bleeding & 8 & 16 & 22 & 44 & 20 & 40 & 1.7 & Accept \\
\hline 7. & $\begin{array}{l}\text { Encourage the mother to empty } \\
\text { bladder }\end{array}$ & 10 & 20 & 25 & 50 & 15 & 30 & 1.9 & Accept \\
\hline 8. & Encouragement of breast feeding & 16 & 32 & 14 & 28 & 20 & 40 & 1.9 & Accept \\
\hline 9. & $\begin{array}{l}\text { Put the newborn skin to skin contact } \\
\text { with mother }\end{array}$ & 6 & 12 & 4 & 8 & 40 & 80 & 1.3 & Poor \\
\hline 10. & $\begin{array}{l}\text { Suction the secretion from the nose } \\
\text { and eye of newborn }\end{array}$ & 7 & 14 & 17 & 34 & 26 & 52 & 1.6 & Poor \\
\hline 11. & Weighting of newborn & 20 & 40 & 10 & 20 & 15 & 30 & 1.9 & Accept \\
\hline 12. & Put band on the newborn baby hand & 27 & 54 & 13 & 26 & 10 & 20 & 2.3 & Accept \\
\hline 13. & $\begin{array}{l}\text { Record mother name, sex, date on the } \\
\text { band }\end{array}$ & 10 & 20 & 20 & 40 & 20 & 40 & 1.8 & Accept \\
\hline
\end{tabular}

Table (4): association between midwives - nurses knowledge and age regarding to mother and newborn care immediately after delivery $(\mathrm{N}=50)$

\begin{tabular}{|c|c|c|c|c|c|c|c|c|}
\hline knowledge & \multicolumn{2}{|c|}{ adequate } & \multicolumn{2}{|c|}{ inadequate } & \multicolumn{2}{|c|}{ Total } & \multirow{2}{*}{$\chi^{2}$ obs. } & \multirow{2}{*}{ Sig } \\
\hline Age & No. & $\%$ & No. & $\%$ & No. & $\%$ & & \\
\hline $20-29$ years & 11 & 22 & 7 & 14 & 18 & 36 & & \multirow{4}{*}{ NS } \\
\hline $30-39$ & 14 & 28 & 6 & 12 & 20 & 40 & & \\
\hline More than 40 years & 6 & 12 & 6 & 12 & 12 & 24 & & \\
\hline Total & 31 & 62 & 19 & 38 & 50 & 100 & & \\
\hline$P \leq 0.05$ & & & If $=2$ & & & & 5.99 & \\
\hline
\end{tabular}


Table(5): association between midwives - nurses practice and age of them during mother and the newborn baby care immediately after delivery $(\mathrm{N}=50)$

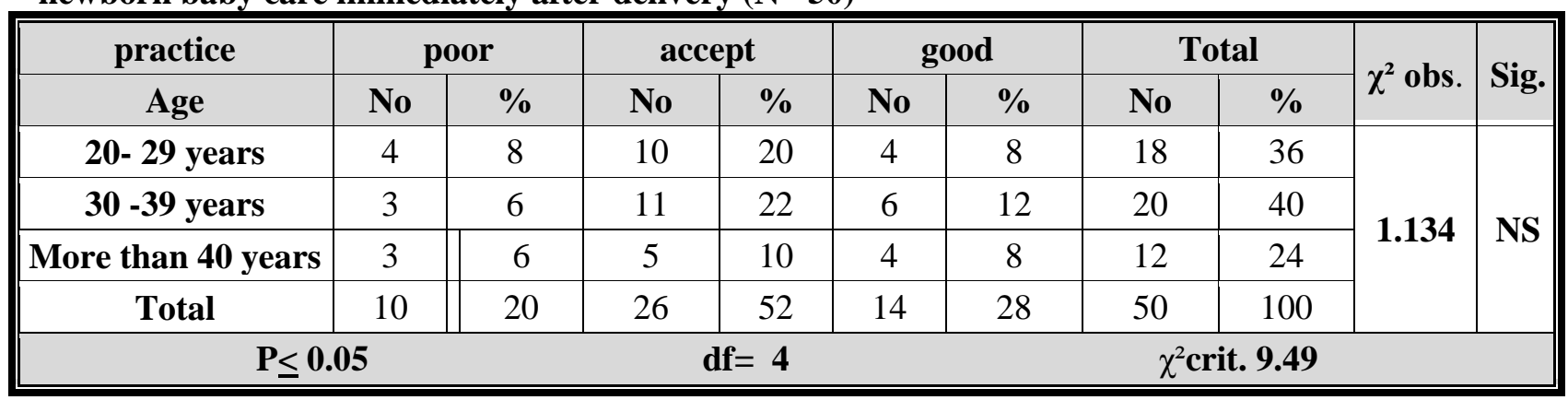

Table (6): Grand Mean of Score and evaluation of midwives - nurses knowledge regarding mother and the newborn baby care immediately after of placenta (fourth stage of labor)

\begin{tabular}{|l|l|l|l|}
\hline NO. & Midwives- nurses knowledge and practice & GMS & evaluation \\
\hline 1. & $\begin{array}{l}\text { Knowledge regarding Mother and newborn care } \\
\text { immediately after birth }\end{array}$ & 1.6 & Adequate \\
\hline 2. & $\begin{array}{l}\text { Practice regarding mother and newborn immediate } \\
\text { after birth }\end{array}$ & 2 & accept \\
\hline
\end{tabular}

\section{DISCUSSION}

Table (1) demonstrates the sociodemographic characteristics of the whole study sample, it shows that there is the highest percentage of Age groups is between (30-39) and constituted $(40 \%)$, status. With relation to level of education the $(74 \%)$ of them were graduated from the secondary nursing school /midwifery . About (60\%) of the study sample had less than five years experience.

Table (2) shows that there were high mean of score in the most of items participant midwives - nurses knowledge regarding mother care immediately after delivery of placenta, with grand mean of score (1.6) were adequate knowledge.

Tables (3) shows that the practice of nurses - midwives is between good and accept while there was low mean scores in some. According to grand mean of scores the nurses midwives practice was accepted with a mean scores (2).

Table (4) shows that (40\%) of total sample was from age group (30-39), with (28\%) of them had adequate knowledge, while only $(12 \%)$ of them had inadequate. In addition the table shows that was no significant difference between midwives- nurse's age and their knowledge.

Table (5) shows that (22\%) of the sample had accepted practice, (12\%) had good practice with in age group (30 -39) which were (40\%) of the total. In addition there was no significant difference between their age and practice.
The present results in table (6) show that the total knowledge of midwives - nurses is adequate according to the grand mean of scores of (1.6). The average practice of midwives nurses is accepted with grand mean scores (2).

The first hours, days and weeks after child birth are dangerous time for mother and newborn most death occur during or immediately after childbirth and this period that determine their well-being and potential for health future (WHO,2010). The present study evaluates the midwives and nurse's knowledge and practces regarding immediate care mother and newborn after birth. It is found that most of the study items not all were (adequate), Whereas the items concerning: breast feeding, skin to skin contact, air war clearance, baby identification were (inadequate). This result is in agreement with Kebalepil (2001) in most items not all, while in breastfeeding item he found that the nurses and midwives have good knowledge about breastfeeding.

Also this result is in disagreement with $\mathrm{El}$ Fatta et. al. (2012) who assessed the nursing care immediately after birth. They stated that the nurses have an average knowledge regarding care of mother and newborn immediately after birth. Moreover, feeding and skin to skin contact Creedy et. al. (2008) who found that the midwives have adequate knowledge regarding skin to skin and high score in breastfeeding knowledge. The result is consistent with Kearvell (2012) who reported that the nurses need to construct nursing care around the mother- infant dyad, with roles and responsibilities that 
incorporate mother- infant and mother nurse relationship in support attachment process. Also this result is in disagreement with Nihidi et. al. (2013) done to evaluate midwives knowledge and attitude on skin to skin contact. They reveal that the midwives have good knowledge and attitude about skin to skin contact.

The present study result disagree with Taha (2011) who stated that the nurses have fair knowledge regarding immediate care of newborn but agreement with air way clearance and baby identification.

In a current study most of item of practice is between accepted and good practice the average practice of midwives and nurse's is accepted. This result is an agreement with El Fattah et. al. (2012) in most of their items, but it is in disagreement in hand washing during contact with newborn and baby and putting identification band. This result is in agreement with Shrestha et. al. (2012) who found more than half of the nursing staff have average practice regarding newborn care. While in consistence with Kabalepile (2001) who found that most of nurses have good practice and provide good care during immediate postpartum period. Therefore, they refreshed courses on safe motherhood for all nurses involved in obstetrics care to improve their skills.

The result is in disagreement with Suad et. al. (2014) they demonstrated that nurse's have poor practice about the care of the newborn immediately after birth. Also this result disagrees with El Sayed et. al. (2012) they stated that the nurses have poor practice regarding immediate care of newborn. Also inconsistence with Taha (2011), who assessed nurses knowledge and practice regarding immediate care in Khartoum Hospital and found that nurses have fair knowledge level and poor practice. Therefore they need training course and periodic assessment.

The current study showed that two fifth of the involved sample were age (30-39) years old. This result is in agreement with that of (Kebalepile, 2001) who evaluate the midwife care during postpartum period in northern Botswana. He found that the majority of the participant midwives were of age between (3039) years. There was no statistical significant association between midwives and nurse's knowledge and practice regarding mother and newborn care immediately after birth and their age (tables, 4 and 5).

This fact can be interpreted in a way that the nurses and midwives governed by restricted rules regarding mother and newborn care immediately after birth in delivery and recovery room. This result is in disagreement with other study that had been done by Sanadin et. al. (2004) indicate that the youngest ages of nurses were found to gain improvement in the knowledge and practice more than the older age nurse- midwives. This means that the older nurses who are working at the Maternity hospital have gained practices concerning care of the pregnant woman during labour from their experiences at the maternity hospitals. Mcinerney et. al. (2000) stated that the older nurses had better performance than the younger probably due to their orientation and benefits that may be gained out of their employment.

\section{CONCLUSIONS}

The study concludes that midwives and nurses have adequate knowledge regarding mother and newborn baby immediately after birth. Midwives and nurses have accepted practice during providing care for mother and newborn baby immediately after birth. It also concludes that there is no significant association between midwives-nurses' knowledge regarding mother and newborn baby care immediate after birth and socio- demographic characteristics. Finally, there is no significant association between midwives-nurse's practice regarding mother and newborn baby care immediate after birth and socio- demographic characteristics.

\section{RECOMMENDATIONS}

The study recommedes that it should providing regular training course especially outside the country on the importance of nursing care and quality of nursing care provide immediately after birth for mother and newborn baby. Continuous educational programmes are necessary to improve the nurses and midwives ability to provide care and dealing with any problem occurring immediately after birth.

\section{REFERENCES}

Abdel El fattah, N.; Nagwa, A.; Zein El dein, B. (2012). Assessment of quality of nursing care provided immediately after birth at university hospital. Life science Journal. 9(4). P.p. 2115-2126

Abdel- Kareem, S., factor affecting the quality of nursing care in intensive care unit: perception of physicians and nurses versus health care consumers (master thesis) Ain shams university, Cairo 2008

EL-sayed, S.; Yomn,Y.; Hamed, M.; Ebtisam, M.; Elsayed and Thanaa, A. 2013). Establishing basic standards of nursing 
protocol at neonatal intensive care units. natural and science.11(4). P.p. 86-92.

Hoda, M.; Nahed, N.; and Sahar, L. women perspective regarding the quality of postpartum nursing care in Ain shams maternity hospital Cairo- Egypt. journal of American science. 8(2). P.p. 366-370.

Mcinerney, S.; Ashwill ,W.; Murray ,S.; James ,R.; Gorrie , M. and Droske , C.(2000). Maternity and Child Nursing. London W.B Sunders. P.p. 364-378.

Nihidi, F.; Tavafian, S.; Heidarzadeh, M.; Hajizadeh,E. (2013). View of Iranian midwives about immediate mother and newborn skin to skin contact at birth. today science journal of humanity. 1(1). P.p. 30-36.

Pual, I.; Phillio, T.; Widome, M.; Hollen beak, C. (2013). Post effectiveness of postnatal home nursing vists for prevention of hospital care of jaundice and dehydration. Pediatrics. (114). P.p.4.

Sandin, F.; Hallord, L.; Axelsson, O.; Uden, G. and Larsson,W.(2004) Midwifery Care. Development of An instrument to
Measuer Quality Based on The World Health Organizations Classification of Care in Normal Birth. Journal Of Clinical Nursing. 13(1). P.p. 75.

Shresth, M.; Singh, R.; Upreti, D. (2012). Quality of care provided to newborn by nursing personnel at $\mathrm{Bp}$ koirala institute of health science kathmandu university medical journal. 7(3). P.p. 27.

Suad, H.; Eqbal,G.; Numan, N. (2014). Evaluation of nurses' practice toward care of newly born infant immediately after birth in delivery.

Taha,F. (2013). Assessment of knowledge, attitude and practice of nurses midwives toward immediate of newborn Khartoum state teaching hospitals. journal of American science. 9(9). P.p.263-270.

The World Health Orgnization WHO. (2010). neonatal mortality rate (per 1000 live birth). Accessed on Nov 23,2010.

Yvonne, C.; Aaron, B. (2009). Normal labor and delivery. Available at http://enemedicin-medscape.com. 